\title{
Updates and Critical Evaluation on Novel Biomarkers for the Malignant Progression of Intraductal Papillary Mucinous Neoplasms of the Pancreas
}

\author{
DEMETRIOS MORIS ${ }^{1 *}$, CHRISTOS DAMASKOS $^{2 *}$, ELEFTHERIOS SPARTALIS $^{3}$, \\ ALEXANDROS PAPALAMPROS ${ }^{4}$, SPYRIDON VERNADAKIS ${ }^{5}$, DIMITRIOS DIMITROULIS ${ }^{2}$, \\ JOHN GRINIATSOS ${ }^{4}$, EVANGELOS FELEKOURAS ${ }^{4}$ and NIKOLAOS NIKITEAS ${ }^{3}$
}

${ }^{1}$ Department of Surgery, The Ohio State University Comprehensive Cancer Center, Columbus, OH, U.S.A.;

${ }^{2} 2$ nd Department of Propedeutic Surgery, University of Athens Medical School, Athens, Greece;

${ }^{3}$ Laboratory of Experimental Surgery and Surgical Research, University of Athens Medical School, Athens, Greece;

${ }^{4}$ First Department of Surgery, University of Athens Medical School, Athens, Greece;

${ }^{5}$ Department of Liver Transplantation and Hepatobiliary-Pancreatic Surgery, King Faisal Specialist Hospital and Research Cancer, Riyadh, Kingdom of Saudi Arabia

\begin{abstract}
Intraductal papillary mucinous neoplasms (IPMNs) are presumed to evolve from low-grade dysplasia to high-grade dysplasia to invasive carcinoma. Resection of lesions before the development of pancreatic cancer may prevent the development of an incurable process as, once IPMNs progress to invasive cancer, the prognosis may be as poor as resected conventional pancreatic ductal adenocarcinoma. Resection of IPMNs, particularly in the setting of high-grade dysplasia, is presumed to provide a survival benefit. IPMNs also present many challenges as the identification of high-grade dysplasia and early invasive carcinoma and the timing and frequency of malignant progression are not yet established. The limited predictive accuracy presents a challenge as pancreatic resection is associated with a risk of substantial morbidity and mortality; $20-30 \%$ and 2-4\%, respectively. Diagnostic armamentarium contains pancreas-protocol computed tomography (CT) scan,
\end{abstract}

This article is freely accessible online.

*These Authors contributed equally to this study.

Correspondence to: Demetrios Moris MD, Ph.D., Department of Surgery, The Ohio State University Comprehensive Cancer Center, The Ohio State University, Columbus, OH 43210, U.S.A. Tel: +1 2164442574, Fax: +1 2164454658, e-mail: dimmoris@yahoo.com

Key Words: Biomarkers, pancreatic cystic lesion, intraductal papillary mucinous neoplasms, IPMN, CEA, CA19-9, KRAS, GNAS, BRAF, hTERT, hedgehog, CDKN2A, P53, STK11, BRG1, $\mathrm{S} 100, \mathrm{CpG}$ island, hypermethylation, mutation, MUC, mAb Das-1, microRNA, peripheral blood cells, review. gadolinium-enhanced magnetic resonance imaging (MRI) with or without magnetic resonance cholangiopancreatography (MRCP) and endoscopic ultrasound (EUS). The most promising method is endoscopic ultrasound-guided fine-needle aspiration (EUS-FNA) as this technique allows analysis of cyst fluid using biomarkers. Until now, in clinical practice, we utilize two biomarkers, carcinoembryonic antigen (CEA) and carbohydrate antigen 19-9 (CA19-9); however, DNA analysis of pancreatic cystic fluid and genomic analysis could offer new tools to the diagnosis and administration of IPMNs. Novel genomic and serum biomarkers could play an important future role to identify those individuals who will benefit from an early operation and those who will benefit from watchful waiting approach. More prospective studies are needed.

Intraductal papillary mucinous neoplasms (IPMNs) of the pancreas represent both an opportunity and a challenge. They represent an opportunity as these lesions are the only radiographically identifiable precursors of pancreatic cancer. These cystic lesions are presumed to evolve from low-grade dysplasia to high-grade dysplasia to invasive carcinoma (1, 2). Resection of lesions before the development of pancreatic cancer may prevent the development of an incurable process as, once IPMNs progress to invasive cancer, the prognosis may be as poor as resected conventional pancreatic ductal adenocarcinoma (3-5). Resection of IPMNs, particularly in the setting of high-grade dysplasia, is presumed to provide a survival benefit. IPMNs also present many challenges as the identification of high-grade dysplasia and early invasive carcinoma and the timing and frequency of malignant progression are not yet established $(6,7)$. 
Currently, the most accurate test for prediction of highgrade dysplasia or invasive disease is dilation of the main pancreatic duct on preoperative imaging (main duct IPMN (MD-IPMN)). Patients who undergo resection for MD-IPMN have an approximately $60 \%$ chance of harboring high-grade dysplasia or invasive disease at the time of resection. This high-risk disease is present in approximately $20-25 \%$ of patients who undergo resection in the absence of a dilated pancreatic duct (branch duct IPMN (BD-IPMN)) (8). This limited predictive accuracy presents a challenge as pancreatic resection continues to be associated with a risk of substantial morbidity and mortality. In high-volume centers performing pancreaticoduodenectomy, the reported major morbidity rates are approximately $20 \%$ to $30 \%$ and mortality rates approximately $2 \%$ to $4 \%(9,10)$.

The aim of this review is to demonstrate and critically evaluate the evolution and the recent updates on the biomarkers related to malignant progression of pancreatic IPMN.

\section{Current Diagnostic Approach}

In general, the diagnosis in IPMNs is associated with the detection of several characteristics of the cysts. These characteristics are related to the prediction of malignancy, MD lesions' involvement and the detection of mural nodule. Concerning the mural nodule, according to reports, the size threshold is $5 \mathrm{~mm}(11,12)$. It is well-known that, theoretically, the modalities of choice are either pancreas-protocol computed tomography (CT) scan or gadolinium-enhanced magnetic resonance imaging (MRI) with magnetic resonance cholangiopancreatography (MRCP). However, in practice, MRI is the preferable imaging method as it succeeds higher contrast resolution in outlining the MD involvement and finding mural nodule. Also, it has the benefit that patients who should be long-term checked avoid repeated radiation exposure (13).

Another imaging method that presents sublime sensitivity and can find mural nodules within IPMNs is endoscopic ultrasound (EUS). However it is more invasive and lacks specificity. On the contrary contrast-enhanced EUS has high specificity (90\%) and contributes to discriminate entities (14).

Nevertheless, the most promising method in the area of diagnostics in IPMNs is endoscopic ultrasound-guided fineneedle aspiration (EUS-FNA). This technique allows the analysis of cyst fluid using biomarkers. It is evident that only adequately trained centers can reserve this analysis, given that the specimen can be easily contaminated. EUS-FNA has the ability to distinguish mucinous from non-mucinous cysts $(15,16)$.

\section{Current Practice and the Updates on the Genomic Field}

Research on the field is mainly focused on the identification of biomarkers, predictive of the natural history of IPMNs, as well as diagnostic between benign and malignant pancreatic diseases. Unfortunately, no reliable and efficient biomarker has been established to serve these purposes (17).

It is commonplace among literature that the carcinoembryonic antigen (CEA) is the most commonly used biomarker for the diagnosis and follow-up of IPMN (18). CEA is a glycoprotein of the cell surface whose levels are elevated in over $60 \%$ of patients with pancreatic ductal adenocarcinoma. It is released from the peripheral cancer cell membrane and, then, is free to enter the systemic circulation. Concerning the diagnosis of IPMN, studies suggest a cut-off of $192 \mathrm{ng} / \mathrm{ml}$. Unfortunately, CEA cannot discern benign from malignant cysts (19). Moreover, it is reported to be equally raised in mucinous cystic neoplasms and in $30 \%$ of the samples it is low (20-25). Therefore, the evaluation of serum CEA level is preferred. The sensitivity of serum CEA concerning malignant and invasive IPMNs is $18 \%$, which is too low to be used as a screening method, especially in high-risk patients. On the other hand, the specificity of serum CEA is approximately $95 \%$, so this marker can be used to rule-in IPMN malignancy. Serum CEA level $>5 \mathrm{ng} / \mathrm{ml}$ is thought to be a potent predictor of malignancy and invasiveness. Nevertheless, it is evident that in order to decide a therapeutic plan that includes treatment modalities of increased severity, such as surgery, an elevated serum CEA level is not a definite marker.

The carbohydrate antigen 19-9 (CA19-9) is the other biomarker often used for the diagnosis of IPMNs $(18,26)$. It is a tumor-associated glycoprotein. Both CA19-9 and CEA are shown to be relatively adequate predictors of the diagnosis and prognosis of ductal adenocarcinoma; however, it seems that CA19-9 is better predictor of malignant status. CA19-9 levels are elevated in $85 \%$ of patients with pancreatic ductal adenocarcinoma. The sensitivity of CA199 is $44 \%$ and the specificity is $85 \%$. Moreover, there is an association between the increased levels of CA19-9 and the presence of invasive IPMN. Consequently, in patients with positive tumor markers, when surgery is decided or indicated, we should not attempt limited resections (27).

Kirsten-ras $(K R A S)$ is an oncogene that encodes a membrane-bound guanosine triphosphate (GTP)-binding protein. It is located on chromosome arm 12p. It is often associated with mutation at the codon $13(1,28)$. Studies do not agree on the frequency of mutations of the KRAS gene as it is ranged from $38.2-100 \%(29,30)$. It is possible that this wide range is correlated to better definition of the lesions. Also, the sensitivity of the chosen screening methodology could affect the variety of these frequencies. Furthermore, as the percentage in low, intermediate and high-grade dysplasias is about $70-90 \%$, it can be assumed that there is no significant difference in the frequency of KRAS mutations in variable grades of dysplasia.

The expression of KRAS mutation can be studied in surgical specimens, in peripheral blood and in the pancreatic 
juice (28). Concerning the pancreatic juice, the expression of $K R A S$ mutation is not a specific biomarker for pancreatic neoplasms as a similar expression could be found in chronic pancreatitis or other inflammatory pancreatic diseases (31). Moreover, if the mutation is present in the main tumor, the changes in the expression of KRAS can be found in the peritumoral region and in other IPMN lesions (31). Kobayashi et al. showed that between patients with and without mutation in the KRAS gene detected, a significant change in the diameter of the main pancreatic duct was noted, so it is possible that the frequency of mutations in the $K R A S$ gene could be correlated to hyper-secretion of mucin. In addition, the pancreatobiliary subtype shows the highest frequency of KRAS mutations, while the intestinal subtype shows the lowest (32). It is understandable that KRAS could be used as a possible indicator for mucinous differentiation of pancreatic cysts. On the other hand, the lack of specific differentiation among the incidence of KRAS mutation in the several stages of dysplasia shows that KRAS cannot be used for the identification of benign and malignant IPMNs. Finally, we should report that if the CEA level is low, then the KRAS testing is extremely valuable for the presence of malignant IPMN $(27,33)$.

Furthermore, GNAS is an oncogene that encodes the guanine nucleotide-binding protein (G-protein) alpha subunit $(\mathrm{Gs}-\alpha)$. It is located on chromosome arm 20q. It is often associated with mutation at the codon 201 (34). GNAS is a very important biomarker given the fact that GNAS mutations are found only in IPMNs $(28,35)$. One hundred percent of the intestinal type displays GNAS mutations, while $71 \%$ of pancreatobiliary type and $51 \%$ of gastric types shows these mutations. Moreover, the GNAS mutation rate in IPMN with distinct pancreatic adenocarcinoma was recently found to be significantly lower than that in IPMN without adenocarcinoma (36). GNAS wild-type and gastric type IPMNs were significantly associated with distinct adenocarcinomas (36). We should mention that in oncocytic IPMNs, GNAS mutations are not detected. In general, GNAS mutations are often in more advanced lesions. A recent experimental study demonstrated that activating mutations in GNAS and KRAS cooperatively promote pancreatic tumorigenesis, which recapitulates IPMN (37).

Another oncogene that has been studied is $B R A F$. BRAF encodes the serine-threonin kinase b-Raf. It is a compound that participates at the RAS/ MAPK pathway, which is very important for the regulation of pivotal cellular functions (38). BRAF is one of the three isoforms of Raf, that is the starting molecule of the kinase cascade (30). It is located on chromosome arm 7q. Concerning IPMNs, while the incidence of mutant $B R A F$ is only $2.7 \%$, both the changes in the Ras/Raf/MEK/ERK/MAP pathway caused by mutant $B R A F$ and the $R A S$ mutation are reported to significantly affect the tumor genesis of IPMNs. Furthermore, studies report that both $B R A F$ and $K R A S$ transformation lead to accelerated course in the progression of tumorigenesis (39).

It is widely known that telomeres are nucleoprotein structures in the ends of chromosomes responsible for the genomic stability. Telomerase, a RNA-dependent DNA polymerase, restores the reduction of telomeres as it elongates the telomeric DNA sequence, but is normally inactivated in human cells (40). The human telomerase reverse transcriptase (hTERT) gene is the catalytic component of telomerase. It is located on chromosome 5 (40). In general, in IPMNs, it is common that the size of telomeres is gradually decreased and hTERT expression is elevated in comparison to non-malignant neoplasms (41).

Another oncogene that has been evaluated in pancreatic oncogenesis is Hedgehog. Hedgehog ( Hh) proteins constitute a family of secreted signaling factors that participate at the regulation of development of tissues (42). One of the genes that belong to the Hh family is sonic hedgehog ( $\mathrm{SHH}$ ) gene and its abnormal activity is reported in IPMNs (43). SHH expression is detected in $68.8 \%$ of intestinal types, $92.8 \%$ of pancreatobiliary types, $38.1 \%$ of null types and in $50 \%$ of unclassified types. Moreover, $\mathrm{SHH}$ expression can be detected in pancreatic juice from IPMN, but not in pancreatitis juice, so by detecting $\mathrm{SHH}$ expression, IPMN can be discriminated from chronic pancreatitis (44). We can assume that $\mathrm{SHH}$ activity is associated with the early stages of IPMNs and that its activation may affect the transformation from benign to malignant dysplasia in IPMN. In addition, $S H H$ expression is found to correlate in metastatic progression to lymph node in malignant IPMN.

There are also investigations in the field of tumor suppressor genes. Cyclin-dependent kinase inhibitor $2 \mathrm{~A} / \mathrm{p} 16$ $(C D K N 2 A)$ is a tumor suppressor gene that encodes the cyclin dependent kinase (Cdk) inhibitor p16Ink4A. It is located on chromosome $9 \mathrm{p}$ (45). Its inactivation due to homozygous deletion, mutation or epigenetic knock-down by methylation appears at late stages of pancreatic carcinogenesis (46). In borderline IPMNs, the inactivation of P16 protein is detected in $10-25 \%$ of the cases, while in the IPMN carcinomas this loss is described in approximately $80-100 \%$ (47). Evidently, the inactivation of P16 is the necessary but not the sufficient treaty in order to induce the alteration from non-invasive IPMN to invasive carcinoma. However, inactivation of P16 alone is reported as the most powerful biomarker in discrimination of IPMN with low-grade/intermediate dysplasia from the IPMN with carcinoma (46).

Another widely known tumor suppressor gene is P53. P53 encodes the proper regulation of cell cycle. It is located on chromosome arm $17 \mathrm{p}$. Studies do not agree on the accurate percentage of mutant P53 gene in IPMN (27.3-52\%); however, the consensus is that, in adenoma dysplasia, we do not detect P53 mutation. On the other hand, P53 mutation is found in $33.3 \%$ of borderline tumor and in $38.5 \%$ of non- 
invasive carcinoma (48). The inactivation of P53 seems to display at a late stage in the carcinogenesis of IPMN. A recent study demonstrated that NOP14 overexpression promoted cell motility, whereas NOP14 inhibition decreased invasive capacity of pancreatic adenocarcinoma cells via P53 mutation stability that was validated as a functional target of NOP14 (49). The NOP14/mutP53 axis suppressed P21 expression at both the transcriptional and post-transcriptional levels via induction of microRNA-17-5p in pancreatic adenocarcinoma cells (49). We should mention that in IPMNs, the inactivation of $P 53$, concomitant with the inactivation of the $P 16$, are found in $20 \%$ of borderline tumors, $33 \%$ of the non-invasive carcinomas, in all the invasive carcinomas and in any adenoma (50). It is understandable that the transformation of IPMN to an invasive carcinoma depends crucially on the loss of action of both P53 and P16.

Serine/threonine kinase 11 (STK11) gene encodes growthsuppressing activity and the regulation of P53-dependent apoptosis. It is located on chromosome arm 19p (51). STK11 mutation is associated with IPMN and pancreatic ductal adenocarcinoma (52). Moreover, there is a particular correlation between STK11 mutation and Peutz-Jegher syndrome. Loss of heterozygosity at $19 \mathrm{p} 13.3$ is detected in all IPMNs from patients with this syndrome and only in $25 \%$ of patients lacking the phenotype of Peutz-Jegher syndrome (53). Knowing that patients with Peutz-Jegher syndrome have an extremely increasing risk of developing pancreatic cancer, IPMN could be a beneficial precursor of pancreatic ductal adenocarcinoma.

Another gene that has been studied is Brahma-related gene $1(B R G 1) . B R G 1$ is an ATPase that encodes a subunit of the SWI/SNF chromatin remodeling complex that makes target genes accessible to transcription factors. It is located on chromosome arm 19p (54). Concerning IPMNs, inactivation of $B R G 1$ is reported in $53.3 \%$ of the lesions. Interestingly, a gradual loss of BRG1 expression is correlated to an increasing degree of dysplasia (55).

Recent studies have investigated the activity of members of the S100 family in IPMNs (56). The S100 family constitutes a group of proteins that participate in vital signaling pathways, such as the $\mathrm{Ca}^{2+}$ signaling network (57, 58). In IPMNs, the levels of expression of several members of this family, such as S100P, are highly elevated in bulk pancreatic tissues, than in non-neoplastic pancreatic tissues. Furthermore, in micro-dissected cells, S100P expression is reported to be increased in pancreatic ductal adenocarcinoma in relation to IPMN cells $(56,59)$. Interestingly, in pancreatic juice, S100P is highly expressed in IPMNs in relation to chronic pancreatitis (60). Therefore, the measurement of S100P levels in pancreatic juice could be used for the discrimination of neoplastic disease from chronic pancreatitis. Moreover, another member of this family is S100 calcium binding protein $\mathrm{A} 4(\mathrm{~S} 100 \mathrm{~A} 4)$ and its expression is related to tumor metastasis (56). S100A4 is expressed only in $7.4 \%$ of adenomas and borderline dysplasias and in $42.9 \%$ of IPMNderived carcinomas (56). We understand that S100A4 is a promising marker of malignancy, given the fact that we could use it for the diagnosis and study of IPMN. Further studies in the activity of S100 family members are needed, so that some of these compounds could be used as biomarkers of pancreatic carcinogenesis (61).

Studies have also focused on the DNA methylation in genes. It is known that cytosine phospho-guanine $(\mathrm{CpG})$ islands are genomic regions with high presence of $\mathrm{CpG}$ sites (62). In more than $80 \%$ of the IPMNs, it is reported that tumor suppressor gene expression by promoter hypermethylation at $\mathrm{CpG}$ islands is silenced. Interestingly, higher grade IPMNs possess a highest number of methylated genes than lower grade IPMNs (63). Significantly, the mismatch repair genes MutL homolog $1(\mathrm{~h} M L H 1)$ and $\mathrm{O}^{6}$-alkylguanine DNA alkyltransferase $(M G M T)$ are found more frequently methylated in the higher grade IPMNs than in lower grade IPMNs (64). We should mention that, in the adenocarcinomas associated with IPMN, hypermethylation involving three or more promoter regions is found in $55 \%$ of the samples, while, in non-invasive IPMNs, $20 \%$ of the samples are found methylated in at three or more gene promoters (65). It is assumable that the pancreatic juice can be analyzed concerning the methylated DNA in order to differentiate the invasive from non-invasive IPMNs before surgery.

Other genes that have been associated with carcinogenesis are mucins. Mucins $(M U C s)$ are genes that are reported to influence homeostasis and carcinogenesis. Particularly in pancreatic cancer $M U C 1$ and $M U C 2$ are showed to be specific markers of aggressive types (66). It has been shown that MUC protein expression can be measured by EUS-FNA. In IPMNs, MUC1 is detectable in $90 \%$ of tubular type invasion, while it is detectable in $8.6 \%$ of borderline IPMNs and in $35.8 \%$ of carcinoma IPMNs (67). We should mention that the detection of MUC1 in cystic fluid of IPMNs is rare (68). In general, over-expression of MUC1 is associated with invasive carcinoma. Moreover, MUC2 is a secretory mucin, associated with the regulation of cell proliferation (66). It is a very promising gene as it is not expressed in pancreatic tissue normally but it can be detected it in intestinal-type IPMN and colloid carcinomas $(29,68)$. Its expression is elevated gradually from adenoma/borderline IPMN to carcinoma in situ, to colloid carcinoma. On the other hand, in ordinary pancreatic ductal adenocarcinomas, only $1 \%$ of the samples express MUC2 (66). Concerning invasive carcinomas developed from IPMN, colloid carcinomas express MUC2 but they do not express MUC1, while only $1 \%$ of tubular adenocarcinomas express MUC2 (60\% express MUC1) (66).

Recently, Das et al. developed a monoclonal antibody, called mAb Das-1, against a colonic epithelial phenotype. 
Both the EUS-FNA cyst fluid analysis (specificity and sensitivity of $100 \%$ and $89 \%$, respectively) and histological specimens from resected high-grade IPMNs (specificity and sensitivity of $95 \%$ and $85 \%$, respectively) showed that Das-1 has potent reactivity (69).

Finally, we should mention microRNAs as a very promising field in the area of biomarkers. MicroRNAs (miRNAs) are small single-stranded RNA molecules that participate at the regulation of gene expression (70). Abnormal expression of miRNAs is observed both in pancreatic adenocarcinoma and its precursor lesions, such as IPMN (71). In particular, miRNA-21 (miR21) and miRNA155 (miR155) expression is significantly up-regulated in invasive IPMNs compared to non-invasive IPMNs and normal pancreatic tissue (72). Also, in IPMNs with carcinoma in situ, both the expression of miR21 and miR155 is up-regulated more than in IPMN adenomas (73).

\section{Peripheral Blood Cell}

A strong link between neutrophil infiltration and malignant progression has been described, with inflammatory mediators released by these cells playing a pivotal role in the crosstalk between neoplastic and inflammatory cells (74). Recently, it was reported that tumorigenesis in the pancreas is associated with significant intra- and peri-tumoral inflammation and failure of protective immunosurveillance (75). Neutrophil activation and proliferation are indicative of TH-1 pathway of cell-mediated immunity involvement (76). Reasonably, the first phase of inflammation is correlated with increased neutrophil expression, whereas the other 2 phases should be correlated with increased lymphocyte expression (17). Thus, despite being non-specific, increased neutrophil-tolymphocyte ratio (NLR) might be indicative of increased active inflammatory process in IPMN-derived malignancies. Peri-pancreatic lymphocyte subsets have divergent effects on tumorigenesis by either suppressing cancer growth via antigen-restricted tumoricidal immune responses $\left(\mathrm{CD}^{+}\right.$ T-cells and Th1-polarized CD4 ${ }^{+}$T-cells) or by promoting tumor progression via induction of immune suppression (myeloid-derived suppressor cells; MDSCs and Th2-deviated CD4 ${ }^{+}$T-cells) $(76,77)$. Another study showed that pancreatic adenocarcinoma-infiltrating $\gamma \delta-\mathrm{T}$ cells are a highly influential lymphocyte subset promoting pancreatic oncogenesis and reducing survival via novel cross-talk with the adaptive immune compartment; Nevertheless, they may also have prognostic significance of survival and response to immunotherapeutic regimen (77). Investigators from our Institution have reported an association between tumorassociated neutrophils (TANs) and advanced IPMN lesions (78). The recent publication of Gemenetzis et al. (79) evaluating the correlation between NLR and platelet-tolymphocyte ratio (PLR) values and the presence of invasive carcinoma in patients with IPMN. Despite the limitations of the study that the authors acknowledge, including its retrospective nature and the non-specificity of the results since blood is a complex fluid with high cellular turnover, the striking finding was that NLR was significantly elevated in patients with IPMN-associated invasive carcinoma in a value higher than 4 (79).

Also, preoperative NLR, in intraductal papillary mucinous carcinoma (IPMC), was significantly higher in patients with IPMC $\left(2,510 \pm 8.4\right.$ cells $\left./ \mathrm{mm}^{3}\right)$ than in patients with IPMN $\left(2,010 \pm 7.1\right.$ cells $\left./ \mathrm{mm}^{3}, p=0.0079\right)$ and healthy volunteers $\left(1,370 \pm 3.3\right.$ cells $\left./ \mathrm{mm}^{3}, p<0.0001\right)(80)$. NLR was significantly reduced after curative tumor resection. The main duct type $(p=0.0231)$ and NLR $>2.074(p=0.0329)$ were independent predictors of IPMC in all patients. Combined criteria, including international consensus guidelines, CA19-9 $>37 \mathrm{IU} / \mathrm{ml}$ and NLR >2.074, showed a high positive predictive value of $78 \%$ and high specificity of $96 \%$ (80).

Table I restates the promising biomarkers in order to study the clinical management of IPMNs.

\section{Future Perspectives}

We are going through an era of individualization of surgical oncology; in fact, surgery -and anticancer research in general- is now way more personalized than ever before and different issues are treated differently. Furthermore, patients with similar conditions can be treated differently. In the case of IPMN, we believe that precision surgery would be a crucial step to improve oncological outcomes and early diagnosis since patient-specific metabolomic and genomic profile evaluation will give surgeons the opportunity to identify those individuals who will benefit from an early operation and those who will benefit from watchful waiting approach.

A recent meta-analysis determined the relationship between specific genetic alterations and malignant transformation in IPMN of the pancreas. The authors demonstrated that the expression of $h T E R T$ was strongly associated with malignant transformation in IPMN, consistent with up-regulation of $h T E R T$ as a key step in progression of IPMN to cancer (67). On the other hand, expression of KRAS and MUC5AC was common but not strongly associated with IPMN histologic progression (67). The quality criteria used here may guide future reporting of genetic markers related to malignant transformation of IPMN.

All in all, increasing evidence suggests that pancreatic cancer progression is not only caused by the intrinsic properties of tumor cells but also stimulated by host systemic and local inflammatory reactions, including immune cells and cytokines, that might develop a tolerogenic or proinflammatory environment that significantly facilitate tumor invasion and metastasis ability (53). Most studies on the field 
Table I. Promising biomarkers in pancreatic cystic lesions.

\begin{tabular}{|c|c|c|c|}
\hline Marker Name & $\begin{array}{c}\text { Marker } \\
\text { abbreviation }\end{array}$ & Function & $\begin{array}{l}\text { Use in clinical } \\
\text { practice }\end{array}$ \\
\hline Carcinoembryonic antigen & CEA & Low sensitivity and elevated specificity for malignant and invasive IPMN & $\checkmark$ \\
\hline Carbohydrate antigen $19-9$ & CA19-9 & Differentiation of invasive from benign IPMNs & $\boldsymbol{\sim}$ \\
\hline Kirsten-ras & KRAS & Detection in approximately $50 \%$ of IPMNs & $\underset{\text { (rarely) }}{\boldsymbol{\checkmark}}$ \\
\hline GNAS complex locus & GNAS & Detection in approximately $60 \%$ of IPMNs, often in more advanced lesions & $*$ \\
\hline $\begin{array}{l}\text { V-raf murine sarcoma viral } \\
\text { oncogene homolog B1 }\end{array}$ & $B R A F$ & Mutation affects tumor genesis of IPMNs & \\
\hline $\begin{array}{l}\text { Human telomerase reverse } \\
\text { transcriptase }\end{array}$ & $\mathrm{h} T E R T$ & Highly expressed in IPMNs in comparison to non-malignant neoplasms & * \\
\hline Sonic hedgehog & SHH & Discrimination of IPMN from chronic pancreatitis & * \\
\hline $\begin{array}{l}\text { Cyclin-dependent kinase } \\
\text { inhibitor } 2 \mathrm{~A} / \mathrm{P} 16\end{array}$ & $C D K N 2 A$ & $\begin{array}{l}\text { Detection of inactivation in approximately } 90 \% \text { of IPMNs, } \\
\text { discrimination of low-grade IPMN from carcinoma IPMN }\end{array}$ & * \\
\hline Tumor protein P53 & tP53 & Not detected mutation in adenoma dysplasia & \\
\hline Serine/threonine kinase 11 & STK11 & Loss of heterozygosity in $100 \%$ of IPMNs in patients with Peutz-Jegher syndrome & \\
\hline Brahma-related gene 1 & $B R G 1$ & Inactivation in approximately $50 \%$ of IPMNs, correlation to dysplasia & \\
\hline S100 protein & S100P & In pancreatic juice, over-expression in IPMNs in relation to chronic pancreatitis & \\
\hline S100 calcium binding protein A4 & S100A4 & Detection in approximately $43 \%$ of IPMNs & $*$ \\
\hline MutL homolog 1 & hMLH1 & Highly methylated in higher grade IPMNs & \\
\hline $\begin{array}{l}\mathrm{O}^{6}-\text { alkylguanine } \\
\text { DNA alkyltransferase }\end{array}$ & $M G M T$ & & \\
\hline Mucin 1 & $M U C 1$ & $\begin{array}{l}\text { Detection in } 90 \% \text { of tubular type invasion and in } 35.8 \% \text { of IPMNs, } \\
\text { overexpression associated with invasive adenocarcinoma }\end{array}$ & \\
\hline Mucin 2 & MUC2 & Detection in intestinal-type IPMN and colloid adenocarcinomas & $*$ \\
\hline $\begin{array}{l}\text { Monoclonal antibody against } \\
\text { a colonic epithelial phenotype }\end{array}$ & mAb Das-1 & $\begin{array}{c}\text { Specificity for high-risk and malignant } \\
\text { IPMNs }\end{array}$ & $*$ \\
\hline microRNAs & $\begin{array}{l}\operatorname{miR} 21 \\
\operatorname{miR} 155\end{array}$ & Up-regulation in invasive IPMNs & $*$ \\
\hline Neutrophil-to-lymphocyte ratio & NLR & $\begin{array}{l}\text { Increase in patients with invasive carcinoma associated with } \\
\text { IPMN, prediction of IPMC in patients with IPMN }\end{array}$ & $*$ \\
\hline
\end{tabular}

The check mark $(\boldsymbol{})$ refers to the biomarkers that are used in clinical practice. The asterisk $(*)$ refers to the most promising biomarkers that are not utilized at the moment.

fail to elucidate the pancreatic oncogenesis pathways and mainly evaluate several biomarkers that could be indicative or epiphenomenon of many cellular or molecular processes (39). Thus, future research should focus on identifying the pathways and mechanisms of pancreatic oncogenesis and tumor progression.

\section{Conclusion}

There is an ongoing interest on the field of IPMN diagnosis and identification of these cases that are more likely to progress to malignancy. According to current guidelines, as we are still unable to clearly understand the extent of MD involvement preoperatively, we should surgically resect both the MD-IPMNs and mixed-type IPMNs. We should punctuate that, despite the increasing interest in the area of biomarkers, in clinical practice, we continue to mainly utilize two biomarkers, CEA and
CA19-9. DNA analysis of pancreatic cystic fluid and genomic analysis could offer new tools to the diagnostic armamentarium in combination with EUS-FNA of pancreatic cyst fluid sampling that could be extremely useful for the discrimination of benign and malignant IPMNs. Recent data also focus on blood/serum markers that could be related to malignant potential and would be easier to collect and apply in daily practice.

All in all, recent research on IPMNs focuses on ways to distinguish low-risk from high-risk lesions and decide which patients need surgery and which could be just under surveillance. However, it is required that more studies will be realized in order to completely understand the nature of these diseases. Therefore, as IPMN might be considered as precursor of pancreatic ductal adenocarcinoma, the understanding of the molecular pathology of this neoplasm could pander other outcome in relation to the therapy of pancreatic ductal adenocarcinoma. 


\section{Conflicts of Interest}

All Authors declare that they have no competing interests.

\section{References}

1 Fritz S, Fernandez-del Castillo C, Mino-Kenudson M, Crippa S, Deshpande V, Lauwers GY, Warshaw AL, Thayer SP and Iafrate AJ: Global genomic analysis of intraductal papillary mucinous neoplasms of the pancreas reveals significant molecular differences compared to ductal adenocarcinoma. Ann Surg 249(3): 440-447, 2009.

2 Maitra A, Fukushima N, Takaori K and Hruban RH: Precursors to invasive pancreatic cancer. Adv Anat Pathol 12(2): 81-91, 2005.

3 Poultsides GA, Reddy S, Cameron JL, Hruban RH, Pawlik TM, Ahuja N, Jain A, Edil BH, Iacobuzio-Donahue CA, Schulick RD and Wolfgang CL: Histopathologic basis for the favorable survival after resection of intraductal papillary mucinous neoplasm-associated invasive adenocarcinoma of the pancreas. Ann Surg 251(3): 470-476, 2010.

4 Yopp AC, Katabi N, Janakos M, Klimstra DS, D'Angelica MI, DeMatteo RP, Fong Y, Brennan MF, Jarnagin WR and Allen PJ: Invasive carcinoma arising in intraductal papillary mucinous neoplasms of the pancreas: A matched control study with conventional pancreatic ductal adenocarcinoma. Ann Surg 253(5): 968-974, 2011.

5 Petrou A, Moris D, Paul Tabet P, David Wensley Richards B and Kourounis G: Ablation of the locally advanced pancreatic cancer: An introduction and brief summary of techniques. J BUON 21(3): 650-658, 2016.

6 Allen PJ: The management of intraductal papillary mucinous neoplasms of the pancreas. Surg Oncol Clin N Am 19(2): 297310,2010

7 Tanaka M, Fernandez-del Castillo C, Adsay V, Chari S, Falconi M, Jang JY, Kimura W, Levy P, Pitman MB, Schmidt CM, Shimizu $\mathrm{M}$, Wolfgang $\mathrm{CL}$, Yamaguchi $\mathrm{K}$ and Yamao $\mathrm{K}$ : International consensus guidelines 2012 for the management of ipmn and mon of the pancreas. Pancreatology 12(3): 183-197, 2012.

8 Salvia R, Fernandez-del Castillo C, Bassi C, Thayer SP, Falconi M, Mantovani W, Pederzoli P and Warshaw AL: Main-duct intraductal papillary mucinous neoplasms of the pancreas: Clinical predictors of malignancy and long-term survival following resection. Ann Surg 239(5): 678-685, 2004.

9 Sadot E, Basturk O, Klimstra DS, Gonen M, Lokshin A, Do RK, D'Angelica MI, DeMatteo RP, Kingham TP, Jarnagin WR and Allen PJ: Tumor-associated neutrophils and malignant progression in intraductal papillary mucinous neoplasms: An opportunity for identification of high-risk disease. Ann Surg 262(6): 1102-1107, 2015.

10 Papalampros A, Niehaus K, Moris D, Fard-Aghaie M, Stavrou G, Margonis AG, Angelou A and Oldhafer K: A safe and feasible "clock-face" duct-to-mucosa pancreaticojejunostomy with a very low incidence of anastomotic failure: A single center experience of 248 patients. J Visc Surg 153(6): 425-431, 2016.

11 Hirono S, Tani M, Kawai M, Okada K, Miyazawa M, Shimizu A, Kitahata $\mathrm{Y}$ and Yamaue $\mathrm{H}$ : The carcinoembryonic antigen level in pancreatic juice and mural nodule size are predictors of malignancy for branch duct type intraductal papillary mucinous neoplasms of the pancreas. Ann Surg 255(3): 517-522, 2012.
12 Ohno E, Itoh A, Kawashima H, Ishikawa T, Matsubara H, Itoh Y, Nakamura Y, Hiramatsu T, Nakamura M, Miyahara R, Ohmiya N, Ishigami M, Katano $\mathrm{Y}$, Goto $\mathrm{H}$ and Hirooka $\mathrm{Y}$ : Malignant transformation of branch duct-type intraductal papillary mucinous neoplasms of the pancreas based on contrastenhanced endoscopic ultrasonography morphological changes: Focus on malignant transformation of intraductal papillary mucinous neoplasm itself. Pancreas 41(6): 855-862, 2012.

13 Seo N, Byun JH, Kim JH, Kim HJ, Lee SS, Song KB, Kim SC, Han DJ, Hong SM and Lee MG: Validation of the 2012 international consensus guidelines using computed tomography and magnetic resonance imaging: Branch duct and main duct intraductal papillary mucinous neoplasms of the pancreas. Ann Surg 263(3): 557-564, 2016.

14 Ohno E, Hirooka Y, Itoh A, Ishigami M, Katano Y, Ohmiya N, Niwa $\mathrm{Y}$ and Goto H: Intraductal papillary mucinous neoplasms of the pancreas: Differentiation of malignant and benign tumors by endoscopic ultrasound findings of mural nodules. Ann Surg 249(4): 628-634, 2009.

15 Genevay M, Mino-Kenudson M, Yaeger K, Konstantinidis IT, Ferrone CR, Thayer S, Castillo CF, Sahani D, Bounds B, Forcione D, Brugge WR and Pitman MB: Cytology adds value to imaging studies for risk assessment of malignancy in pancreatic mucinous cysts. Ann Surg 254(6): 977-983, 2011.

16 Ono J, Yaeger KA, Genevay M, Mino-Kenudson M, Brugge WR and Pitman MB: Cytological analysis of small branch-duct intraductal papillary mucinous neoplasms provides a more accurate risk assessment of malignancy than symptoms. Cytojournal 8: 21, 2011.

17 Moris D and Felekouras E: The oncogenesis in patients with pancreatic intraductal papillary mucinous neoplasms: Taking the thread from the beginning. Ann Surg, 2017. doi: 10.1097/ SLA.0000000000002163. [Epub ahead of print]

18 Sandblom G, Granroth S and Rasmussen IC: Tps, ca 19-9, vegf-a, and cea as diagnostic and prognostic factors in patients with mass lesions in the pancreatic head. Ups J Med Sci 113(1): 57-64, 2008.

19 Brugge WR, Lewandrowski K, Lee-Lewandrowski E, Centeno BA, Szydlo T, Regan S, del Castillo CF and Warshaw AL: Diagnosis of pancreatic cystic neoplasms: A report of the cooperative pancreatic cyst study. Gastroenterology 126(5): 1330-1336, 2004.

20 Correa-Gallego C, Warshaw AL and Fernandez-del Castillo C: Fluid CEA in IPMNS: A useful test or the flip of a coin? Am J Gastroenterol 104(3): 796-797, 2009.

21 Pais SA, Attasaranya S, Leblanc JK, Sherman S, Schmidt CM and DeWitt J: Role of endoscopic ultrasound in the diagnosis of intraductal papillary mucinous neoplasms: Correlation with surgical histopathology. Clin Gastroenterol Hepatol 5(4): 489-495, 2007.

22 Ngamruengphong S, Bartel MJ and Raimondo M: Cyst carcinoembryonic antigen in differentiating pancreatic cysts: A meta-analysis. Dig Liver Dis 45(11): 920-926, 2013.

23 Othman MO, Patel M, Dabizzi E, Asbun HJ, Stauffer J, Wallace MB, Woodward TA and Raimondo M: Carcino embryonic antigen and long-term follow-up of mucinous pancreatic cysts including intraductal papillary mucinous neoplasm. Dig Liver Dis 44(10): 844-848, 2012.

24 Park WG, Mascarenhas R, Palaez-Luna M, Smyrk TC, O'Kane D, Clain JE, Levy MJ, Pearson RK, Petersen BT, Topazian MD, Vege SS and Chari ST: Diagnostic performance of cyst fluid carcinoembryonic antigen and amylase in histologically confirmed pancreatic cysts. Pancreas 40(1): 42-45, 2011. 
25 Nagula S, Kennedy T, Schattner MA, Brennan MF, Gerdes H, Markowitz AJ, Tang L and Allen PJ: Evaluation of cyst fluid cea analysis in the diagnosis of mucinous cysts of the pancreas. J Gastrointest Surg 14(12): 1997-2003, 2010.

26 Katz MH, Varadhachary GR, Fleming JB, Wolff RA, Lee JE, Pisters PW, Vauthey JN, Abdalla EK, Sun CC, Wang H, Crane CH, Lee JH, Tamm EP, Abbruzzese JL and Evans DB: Serum CA $19-9$ as a marker of resectability and survival in patients with potentially resectable pancreatic cancer treated with neoadjuvant chemoradiation. Ann Surg Oncol 17(7): 1794-1801, 2010.

27 Fritz S, Hackert T, Hinz U, Hartwig W, Buchler MW and Werner $\mathrm{J}$ : Role of serum carbohydrate antigen 19-9 and carcinoembryonic antigen in distinguishing between benign and invasive intraductal papillary mucinous neoplasm of the pancreas. Br J Surg 98(1): 104-110, 2011.

28 Tan MC, Basturk O, Brannon AR, Bhanot U, Scott SN, Bouvier $\mathrm{N}$, LaFemina J, Jarnagin WR, Berger MF, Klimstra D and Allen PJ: GNAS and KRAS mutations define separate progression pathways in intraductal papillary mucinous neoplasm-associated carcinoma. J Am Coll Surg 220(5): 845-854, 2015.

29 Jang JY, Park YC, Song YS, Lee SE, Hwang DW, Lim CS, Lee HE, Kim WH and Kim SW: Increased K-RAS mutation and expression of s100a4 and MUC2 protein in the malignant intraductal papillary mucinous tumor of the pancreas. J Hepatobiliary Pancreat Surg 16(5): 668-674, 2009.

30 Schonleben F, Qiu W, Remotti HE, Hohenberger W and Su GH: Pik3ca, kras, and braf mutations in intraductal papillary mucinous neoplasm/carcinoma (ipmn/c) of the pancreas. Langenbecks Arch Surg 393(3): 289-296, 2008.

31 Tatarian T and Winter JM: Genetics of pancreatic cancer and its implications on therapy. Surg Clin North Am 96(6): 1207-1221, 2016.

32 Okabayashi T, Kobayashi M, Nishimori I, Sugimoto T, Namikawa T, Okamoto K, Okamoto N, Kosaki T, Onishi S and Araki K: Clinicopathological features and medical management of intraductal papillary mucinous neoplasms. J Gastroenterol Hepatol 21(2): 462-467, 2006.

33 Wang W, Zhang L, Chen L, Wei J, Sun Q, Xie Q, Zhou X, Zhou D, Huang P, Yang Q, Xie H, Zhou L and Zheng S: Serum carcinoembryonic antigen and carbohydrate antigen 19-9 for prediction of malignancy and invasiveness in intraductal papillary mucinous neoplasms of the pancreas: A meta-analysis. Biomed Rep 3(1): 43-50, 2015.

34 Dal Molin M, Matthaei H, Wu J, Blackford A, Debeljak M, Rezaee N, Wolfgang CL, Butturini G, Salvia R, Bassi C, Goggins MG, Kinzler KW, Vogelstein B, Eshleman JR, Hruban RH and Maitra A: Clinicopathological correlates of activating gnas mutations in intraductal papillary mucinous neoplasm (IPMN) of the pancreas. Ann Surg Oncol 20(12): 3802-3808, 2013.

35 Wu J, Matthaei H, Maitra A, Dal Molin M, Wood LD, Eshleman JR, Goggins M, Canto MI, Schulick RD, Edil BH, Wolfgang CL, Klein AP, Diaz LA Jr., Allen PJ, Schmidt CM, Kinzler KW, Papadopoulos N, Hruban RH and Vogelstein B: Recurrent GNAS mutations define an unexpected pathway for pancreatic cyst development. Sci Transl Med 3(92): 92ra66, 2011.

36 Ideno N, Ohtsuka T, Matsunaga T, Kimura H, Watanabe Y, Tamura K, Aso T, Aishima S, Miyasaka Y, Ohuchida K, Ueda J, Takahata S, Oda Y, Mizumoto K and Tanaka M: Clinical significance of gnas mutation in intraductal papillary mucinous neoplasm of the pancreas with concomitant pancreatic ductal adenocarcinoma. Pancreas 44(2): 311-320, 2015.
37 Taki K, Ohmuraya M, Tanji E, Komatsu H, Hashimoto D, Semba K, Araki K, Kawaguchi Y, Baba H and Furukawa T: GNAS(r201h) and $\mathrm{KRAS}(\mathrm{g} 12 \mathrm{~d})$ cooperate to promote murine pancreatic tumorigenesis recapitulating human intraductal papillary mucinous neoplasm. Oncogene 35(18): 2407-2412, 2016.

38 Heestand GM and Kurzrock R: Molecular landscape of pancreatic cancer: Implications for current clinical trials. Oncotarget 6(7): 4553-4561, 2015.

39 Zhou L, Baba Y, Kitano Y, Miyake K, Zhang X, Yamamura K, Kosumi K, Kaida T, Arima K, Taki K, Higashi T, Imai K, Hashimoto D, Yamashita Y, Chikamoto A, Beppu T, Tan X and Baba H: KRAS, BRAF, and PIK3ca mutations, and patient prognosis in 126 pancreatic cancers: Pyrosequencing technology and literature review. Med Oncol 33(4): 32, 2016.

40 Ramlee MK, Wang J, Toh WX and Li S: Transcription regulation of the human telomerase reverse transcriptase (HTERT) gene. Genes (Basel) 7(8): pii: E50, 2016.

41 Hashimoto Y, Murakami Y, Uemura K, Hayashidani Y, Sudo T, Ohge H, Fukuda E, Shimamoto F, Sueda T and Hiyama E: Telomere shortening and telomerase expression during multistage carcinogenesis of intraductal papillary mucinous neoplasms of the pancreas. J Gastrointest Surg 12(1): 17-28, 2008.

42 Gan GN and Jimeno A: Emerging from their burrow: Hedgehog pathway inhibitors for cancer. Expert Opin Investig Drugs 25(10): 1153-1166, 2016.

43 Han L, Ma J, Duan W, Zhang L, Yu S, Xu Q, Lei J, Li X, Wang Z, Wu Z, Huang JH, Wu E, Ma Q and Ma Z: Pancreatic stellate cells contribute pancreatic cancer pain via activation of shh signaling pathway. Oncotarget 7(14): 18146-18158, 2016.

44 Jang KT, Lee KT, Lee JG, Choi SH, Heo JS, Choi DW and Ahn $\mathrm{G}$ : Immunohistochemical expression of sonic hedgehog in intraductal papillary mucinous tumor of the pancreas. Appl Immunohistochem Mol Morphol 15(3): 294-298, 2007.

45 Maitra A and Hruban RH: Pancreatic cancer. Annu Rev Pathol 3: 157-188, 2008.

46 Campa D, Pastore M, Gentiluomo M, Talar-Wojnarowska R, Kupcinskas J, Malecka-Panas E, Neoptolemos JP, Niesen W, Vodicka P, Delle Fave G, Bueno-de-Mesquita HB, Gazouli M, Pacetti P, Di Leo M, Ito H, Kluter H, Soucek P, Corbo V, Yamao K, Hosono S, Kaaks R, Vashist Y, Gioffreda D, Strobel O, Shimizu Y, Dijk F, Andriulli A, Ivanauskas A, Bugert P, Tavano F, Vodickova L, Zambon CF, Lovecek M, Landi S, Key TJ, Boggi U, Pezzilli R, Jamroziak K, Mohelnikova-Duchonova B, Mambrini A, Bambi F, Busch O, Pazienza V, Valente R, Theodoropoulos GE, Hackert T, Capurso G, Cavestro GM, Pasquali C, Basso D, Sperti C, Matsuo K, Buchler M, Khaw KT, Izbicki J, Costello E, Katzke V, Michalski C, Stepien A, Rizzato $\mathrm{C}$ and Canzian F: Functional single nucleotide polymorphisms within the cyclin-dependent kinase inhibitor $2 \mathrm{a} / 2 \mathrm{~b}$ region affect pancreatic cancer risk. Oncotarget 7(35): 57011-57020, 2016.

47 Biankin AV, Biankin SA, Kench JG, Morey AL, Lee CS, Head DR, Eckstein RP, Hugh TB, Henshall SM and Sutherland RL: Aberrant p16(ink4a) and dpc4/smad4 expression in intraductal papillary mucinous tumours of the pancreas is associated with invasive ductal adenocarcinoma. Gut 50(6): 861-868, 2002.

48 Abe K, Suda K, Arakawa A, Yamasaki S, Sonoue H, Mitani K and Nobukawa B: Different patterns of p16ink4a and p53 protein expressions in intraductal papillary-mucinous neoplasms and pancreatic intraepithelial neoplasia. Pancreas 34(1): 85-91, 2007. 
49 Du Y, Liu Z, You L, Hou P, Ren X, Jiao T, Zhao W, Li Z, Shu $\mathrm{H}$, Liu $\mathrm{C}$ and Zhao YP: Pancreatic cancer progression relies upon mutant p53-induced oncogenic signaling mediated by NOP14. Cancer Res, pii: canres.2339.2016, 2017. [Epub ahead of print]

50 Wada K: P16 and p53 gene alterations and accumulations in the malignant evolution of intraductal papillary-mucinous tumors of the pancreas. J Hepatobiliary Pancreat Surg 9(1): 76-85, 2002.

51 Childs EJ, Mocci E, Campa D, Bracci PM, Gallinger S, Goggins M, Li D, Neale RE, Olson SH, Scelo G, Amundadottir LT, Bamlet WR, Bijlsma MF, Blackford A, Borges M, Brennan P, Brenner H, Bueno-de-Mesquita HB, Canzian F, Capurso G, Cavestro GM, Chaffee KG, Chanock SJ, Cleary SP, Cotterchio M, Foretova L, Fuchs C, Funel N, Gazouli M, Hassan M, Herman JM, Holcatova I, Holly EA, Hoover RN, Hung RJ, Janout V, Key TJ, Kupcinskas J, Kurtz RC, Landi S, Lu L, Malecka-Panas E, Mambrini A, Mohelnikova-Duchonova B, Neoptolemos JP, Oberg AL, Orlow I, Pasquali C, Pezzilli R, Rizzato C, Saldia A, Scarpa A, Stolzenberg-Solomon RZ, Strobel O, Tavano F, Vashist YK, Vodicka P, Wolpin BM, Yu H, Petersen GM, Risch HA and Klein AP: Common variation at 2p13.3, 3q29, 7p13 and 17q25.1 associated with susceptibility to pancreatic cancer. Nat Genet 47(8): 911-916, 2015.

52 Hong SM, Park JY, Hruban RH and Goggins M: Molecular signatures of pancreatic cancer. Arch Pathol Lab Med 135(6): 716-727, 2011.

53 McGarrity TJ, Amos CI and Baker MJ: Peutz-jeghers syndrome. In: Genereviews(r). Pagon RA, Adam MP, Ardinger HH, Wallace SE, Amemiya A, Bean LJH, Bird TD, Ledbetter N, Mefford HC, Smith RJH and Stephens K (eds.). Seattle (WA), 1993

54 Wang G, Fu Y, Hu F, Lan J, Xu F, Yang X, Luo X, Wang J and $\mathrm{Hu}$ J: Loss of BRG1 induces CRC cell senescence by regulating p53/p21 pathway. Cell Death Dis 8(2): e2607, 2017.

55 Dal Molin M, Hong SM, Hebbar S, Sharma R, Scrimieri F, de Wilde RF, Mayo SC, Goggins M, Wolfgang CL, Schulick RD, Lin MT, Eshleman JR, Hruban RH, Maitra A and Matthaei H: Loss of expression of the swi/snf chromatin remodeling subunit brg $1 /$ smarca 4 is frequently observed in intraductal papillary mucinous neoplasms of the pancreas. Hum Pathol 43(4): 585$591,2012$.

56 Huang S, Zheng J, Huang Y, Song L, Yin Y, Ou D, He S, Chen $X$ and Ouyang $X$ : Impact of s100a4 expression on clinicopathological characteristics and prognosis in pancreatic cancer: A meta-analysis. Dis Markers 2016: 8137378, 2016.

57 Moris D, Theocharis S, Davakis S, Patelis N, Agrogiannis G, Vlachos IS, Spartalis E, Athanasiou A, Bakoyiannis C, Perrea DN and Georgopoulos S: Serum calprotectin as a novel biomarker in abdominal aortic aneurysm pathogenesis and progression: Preliminary data from experimental model in rats. Curr Vasc Pharmacol, 2017. doi: 10.2174/15701611156661 70202155724 [Epub ahead of print]

58 Moris D, Spartalis E, Angelou A, Margonis GA, Papalambros A, Petrou A, Athanasiou A, Schizas D, Dimitroulis D and Felekouras E: The value of calprotectin s100a8/a9 complex as a biomarker in colorectal cancer: A systematic review. J BUON 21(4): 859-866, 2016.

59 Leclerc E and Vetter SW: The role of s100 proteins and their receptor rage in pancreatic cancer. Biochim Biophys Acta 1852(12): 2706-2711, 2015.
60 Ohuchida K, Mizumoto K, Egami T, Yamaguchi H, Fujii K, Konomi H, Nagai E, Yamaguchi K, Tsuneyoshi M and Tanaka $\mathrm{M}: \mathrm{S} 100 \mathrm{p}$ is an early developmental marker of pancreatic carcinogenesis. Clin Cancer Res 12(18): 5411-5416, 2006.

61 Moris D, Felekouras E and Linos D: Global surgery initiative in greece: More than an essential initiative. Lancet 388(10048): $957,2016$.

62 Tirado-Magallanes R, Rebbani K, Lim R, Pradhan S and Benoukraf T: Whole genome DNA methylation: Beyond genes silencing. Oncotarget 8(3): 5629-5637, 2017.

63 Henriksen SD, Madsen PH, Krarup H and Thorlacius-Ussing O: DNA hypermethylation as a blood-based marker for pancreatic cancer: A literature review. Pancreas 44(7): 1036-1045, 2015.

64 Bobustuc GC, Patel A, Thompson M, Srivenugopal KS, Frick J, Weese $\mathbf{J}$ and Konduri SD: MGMT inhibition suppresses survivin expression in pancreatic cancer. Pancreas 44(4): 626-635, 2015.

65 Hong SM, Omura N, Vincent A, Li A, Knight S, Yu J, Hruban RH and Goggins $\mathrm{M}$ : Genome-wide cpg island profiling of intraductal papillary mucinous neoplasms of the pancreas. Clin Cancer Res 18(3): 700-712, 2012.

66 Kaur S, Kumar S, Momi N, Sasson AR and Batra SK: Mucins in pancreatic cancer and its microenvironment. Nat Rev Gastroenterol Hepatol 10(10): 607-620, 2013.

67 Nissim S, Idos GE and Wu B: Genetic markers of malignant transformation in intraductal papillary mucinous neoplasm of the pancreas: A meta-analysis. Pancreas 41(8): 1195-1205, 2012.

68 Adsay NV, Merati K, Basturk O, Iacobuzio-Donahue C, Levi E, Cheng JD, Sarkar FH, Hruban RH and Klimstra DS: Pathologically and biologically distinct types of epithelium in intraductal papillary mucinous neoplasms: Delineation of an "intestinal" pathway of carcinogenesis in the pancreas. Am J Surg Pathol 28(7): 839-848, 2004.

69 Das KK, Xiao H, Geng X, Fernandez-Del-Castillo C, MoralesOyarvide V, Daglilar E, Forcione DG, Bounds BC, Brugge WR, Pitman MB, Mino-Kenudson M and Das KM: Mab das-1 is specific for high-risk and malignant intraductal papillary mucinous neoplasm (IPMN). Gut 63(10): 1626-1634, 2014.

70 Adams BD, Parsons C, Walker L, Zhang WC and Slack FJ: Targeting noncoding RNAS in disease. J Clin Invest 127(3): 761-771, 2017.

71 Hernandez YG and Lucas AL: Microrna in pancreatic ductal adenocarcinoma and its precursor lesions. World J Gastrointest Oncol 8(1): 18-29, 2016.

72 Caponi S, Funel N, Frampton AE, Mosca F, Santarpia L, Van der Velde AG, Jiao LR, De Lio N, Falcone A, Kazemier G, Meijer GA, Verheul HM, Vasile E, Peters GJ, Boggi U and Giovannetti E: The good, the bad and the ugly: A tale of mir-101, mir-21 and mir-155 in pancreatic intraductal papillary mucinous neoplasms. Ann Oncol 24(3): 734-741, 2013.

73 Habbe N, Koorstra JB, Mendell JT, Offerhaus GJ, Ryu JK, Feldmann G, Mullendore ME, Goggins MG, Hong SM and Maitra A: MicroRNA mir-155 is a biomarker of early pancreatic neoplasia. Cancer Biol Ther 8(4): 340-346, 2009.

74 Gregory AD and Houghton AM: Tumor-associated neutrophils: New targets for cancer therapy. Cancer Res 71(7): 2411-2416, 2011.

75 Steele CW, Jamieson NB, Evans TR, McKay CJ, Sansom OJ, Morton JP and Carter CR: Exploiting inflammation for therapeutic gain in pancreatic cancer. Br J Cancer 108(5): 9971003, 2013. 
76 Moris D, Lu L and Qian S: Mechanisms of liver-induced tolerance. Curr Opin Organ Transplant 22(1): 71-78, 2017.

77 Daley D, Zambirinis CP, Seifert L, Akkad N, Mohan N, Werba G, Barilla R, Torres-Hernandez A, Hundeyin M, Mani VR, Avanzi A, Tippens D, Narayanan R, Jang JE, Newman E, Pillarisetty VG, Dustin ML, Bar-Sagi D, Hajdu C and Miller G: Gammadelta $\mathrm{T}$ cells support pancreatic oncogenesis by restraining alphabeta $\mathrm{t}$ cell activation. Cell 166(6): 14851499.e15, 2016.

78 Reid MD, Basturk O, Thirabanjasak D, Hruban RH, Klimstra DS, Bagci P, Altinel D and Adsay V: Tumor-infiltrating neutrophils in pancreatic neoplasia. Mod Pathol 24(12): 1612-1619, 2011.

79 Gemenetzis G, Bagante F, Griffin JF, Rezaee N, Javed AA, Manos LL, Lennon AM, Wood LD, Hruban RH, Zheng L, Zaheer A, Fishman EK, Ahuja N, Cameron JL, Weiss MJ, He J and
Wolfgang CL: Neutrophil-to-lymphocyte ratio is a predictive marker for invasive malignancy in intraductal papillary mucinous neoplasms of the pancreas. Ann Surg, 2016. [Epub ahead of print] 80 Arima K, Okabe H, Hashimoto D, Chikamoto A, Kuroki H, Taki K, Kaida T, Higashi T, Nitta H, Komohara Y, Beppu T, Takeya $\mathrm{M}$ and Baba $\mathrm{H}$ : The neutrophil-to-lymphocyte ratio predicts malignant potential in intraductal papillary mucinous neoplasms. J Gastrointest Surg 19(12): 2171-2177, 2015.

Received March 17, 2017 Revised March 31, 2017 Accepted April 3, 2017 